\title{
A Delphi Study Investigating Clinicians' Views on Access to, Delivery of, and Adaptations of MBCT in the UK Clinical Settings
}

\author{
Kate Williams ${ }^{1,2}$ (1) $\cdot$ Samantha Hartley ${ }^{1,3} \cdot$ Peter Taylor $^{1}$
}

Accepted: 13 July 2021 / Published online: 30 July 2021

(c) The Author(s) 2021

\begin{abstract}
Objectives Mindfulness-based cognitive therapy (MBCT) is a well-evidenced relapse-prevention intervention for depression with a growing evidence-base for use in other clinical populations. The UK initiatives have outlined plans for increasing access to MBCT in clinical settings, although evidence suggests that access remains limited. Given the increased popularity and access to MBCT, there may be deviations from the evidence-base and potential risks of harm. We aimed to understand what clinicians believe should be best clinical practice regarding access to, delivery of, and adaptations to MBCT.

Methods We employed a two-stage Delphi methodology. First, to develop statements around best practices, we consulted five mindfulness-based experts and reviewed the literature. Second, a total of 59 statements were taken forward into three survey rating rounds.

Results Twenty-nine clinicians completed round one, with 25 subsequently completing both rounds two and three. Forty-four statements reached consensus; 15 statements did not. Clinicians agreed with statements regarding sufficient preparation for accessing MBCT, adherence to the evidence-base and good practice guidelines, consideration of risks, sufficient access to training, support, and resources within services, and carefully considered adaptations. The consensus was not reached on statements which reflected a lack of evidence-base for specific clinical populations or the complex decision-making processes involved in delivering and making adaptations to MBCT.

Conclusions Our findings highlight the delicate balance of maintaining a client-centred and transparent approach whilst adhering to the evidence-base in clinical decisions around access to, delivery of, and adaptations in MBCT and have important wide-reaching implications.
\end{abstract}

Keywords MBCT $\cdot$ Mindfulness $\cdot$ Implementation $\cdot$ Delphi $\cdot$ Clinician views $\cdot$ Staff views

Mindfulness-based cognitive therapy (MBCT) aims to teach new ways of relating to inner experience (e.g., thoughts, emotions, sensations) through mindfulness-based meditation alongside psychoeducation around depression and negative thinking styles (Segal et al., 2013). MBCT is an NICE-recommended (National Institute for Health and Care Excellence) intervention for people who have experienced at least two previous 'episodes' of major depression (Kuyken et al.,

Kate Williams

kate.williams-4@manchester.ac.uk

1 Division of Psychology \& Mental Health, School of Health Sciences, University of Manchester, Manchester Academic Health Sciences Centre, Manchester M13 9PL, UK

2 Greater Manchester Mental Health NHS Foundation Trust, Manchester, UK

3 Pennine Care NHS Foundation Trust, Manchester, UK
2016; Segal et al., 2013). MBCT has been shown to reduce the risk of relapse up to 60 weeks post-MBCT, compared with treatment as usual (TAU), in a meta-analysis of nine randomised controlled trials (RCTs; Kuyken et al., 2016). Since its initial development, MBCT has been adapted for use in a range of clinical populations including people with a diagnosis of current depression (Goldberg et al., 2019), bipolar disorder (Lovas \& Schuman-Olivier, 2018), social anxiety (Strege et al., 2018), and post-traumatic stress disorder (PTSD; Boyd et al., 2018). Furthermore, another meta-analysis reported that across 14 RCTs including 2077 participants, MBCT was more effective than TAU in preventing relapse, although this also included participants with remitted, current, and bipolar depression (McCartney et al., 2021).

Following recommendations from the Mindful Nation report (Mindfulness All Party Parliamentary Group, 
2015), there has been a recent push to increase the delivery of MBCT in the UK through the Improving Access to Psychological Therapy (IAPT) programme which is primarily designed to provide treatment for those with depression and/or anxiety. However, evidence suggests that MBCT is not being accessed in line with either NICE guidance or MBCT implementation guidelines across the NHS (Kuyken et al., 2012). Specifically, Crane and Kuyken (2013) reported that $59 \%$ of services offered no MBCT provision, with only 9\% reporting a 'thriving' MBCT service. More recently, Rycroft-Malone et al., (;2017, 2019) reported that only $4 / 40$ services were delivering MBCT in accordance with NICE guidelines. The authors reported that access to MBCT in the NHS remains limited, with reports of services deviating from evidence-based MBCT through developing an adapted hybrid of MBCT to accommodate service restrictions (Rycroft-Malone et al., ;2017, 2019). In light of the excitement around MBCT and related MBIs, there is a risk that whilst much research and care goes into the initial design and testing of an intervention, broad methods of implementation might risk diluting the outcomes. Indeed, Dimidjian and Segal (2015) proposed that careful implementation is a key challenge for the next phase of research into MBCT (and related MBIs).

MBCT, alongside other mindfulness-based interventions (MBIs), has become increasingly popular in the UK and internationally (Morone et al., 2017), reflected in the wide range of available courses, self-help books, and mindfulness app availability (e.g., Headspace; Puddicombe, 2010), as well as freely available, yet often unmonitored, online materials. Alongside the increased popularity of MBCT, there appears to be increased conviction in and assumptions that MBCT, and related MBIs, may function as a 'panacea' (van Dam et al., 2018). In response, some MBCT researchers are advocating for a more cautious approach towards implementation, incorporating an awareness of the limitations and unknowns alongside the benefits of MBCT (Farias \& Wikholm, 2016; van Dam et al., 2018). With increased popularity comes the danger that delivery of MBCT may deviate from the evidence-base, particularly in clinical services often limited by funding and resource restrictions.

As a result of busy and overstretched services, services may make adaptations to MBCT. The British Association for Mindfulness-based Approaches (BAMBA) good practice guidelines (GPG; Crane, 2011) highlight the importance of adhering to the evidence-base when teaching MBCT. Additionally, others have reflected on how minor adaptations in terms of client group or context may be needed, but propose that caution should be exercised to ensure that adaptations stay in line with the theoretical underpinnings of and evidence-base for MBCT (Crane et al., 2016; Dimidjian \& Segal, 2015). Ultimately, adaptations made to MBCT, without consideration of the underlying evidence-base, may risk going against guidelines and/or the evidence-base.

Not delivering MBCT in line with MBCT guidelines may increase the risk of exposing clients to potential harm (Britton, 2019). Studies have suggested that engaging in meditation can, in some participants, induce disturbances in perception (e.g., hallucinations), affective (e.g., paranoia), somatic (e.g., sleep), and behavioural states (e.g., anhedonia), as well as a loss in the sense of self and social impairment (Lindahl et al., 2017). Others have proposed that such harm arises more from participants taking part in intense meditative activities (e.g., silent retreats) as opposed to comparatively shorter, less intense practices typically found within MBCT (Baer et al., 2019). However, there are reports of negative effects resulting from shorter practices, similar to those taught within MBCT (Lindahl et al., 2017).

Despite the increasing popularity of MBCT, access to MBCT in the UK health service remains limited. Furthermore, adaptations to or failure to deliver MBCT in line with the guidelines may lead to deviations from the evidencebase and to the potential for harm. Therefore, we aimed to assess the views of those delivering MBCT in the UK clinical settings with respect to best practices for MBCT. We anticipated that the results of this study would further extend our understanding of what constitutes best clinical practice amongst the expert clinicians actually delivering MBCT. Therefore, through using a Delphi methodology, we aimed to develop consensus amongst clinicians' views with regards to sufficient access to, delivery of (with consideration of client population, risks, adherence to good practice guidelines, teacher training and personal meditation practice, service support, and sufficient resources), and adaptations to MBCT.

\section{Method}

This study used a Delphi approach, defined as an iterative process which is designed to move group opinion towards a group consensus (de Meyrick, 2003; Graham \& Milne, 2003; Hasson et al., 2000). This Delphi study was adapted to incorporate two stages. Stage one invited consultation with 'experts' in either MBCT and/or MBIs to inform the development of the statements. Stage two included an online survey inviting expert clinicians to rate statements across three rounds; online Delphi methods have been shown to be feasible (Khodyakov et al., 2020). Figure 1 below details the Delphi procedure outline. All participants gave informed consent, and ethical approval for both stages was given by The Psychology and Mental Health Division Panel at The University of Manchester. Additionally, two external clinicians were consulted and gave positive feedback regarding the design, feasibility, and accessibility (Supplementary Material S1). 
Fig. 1 Delphi procedure

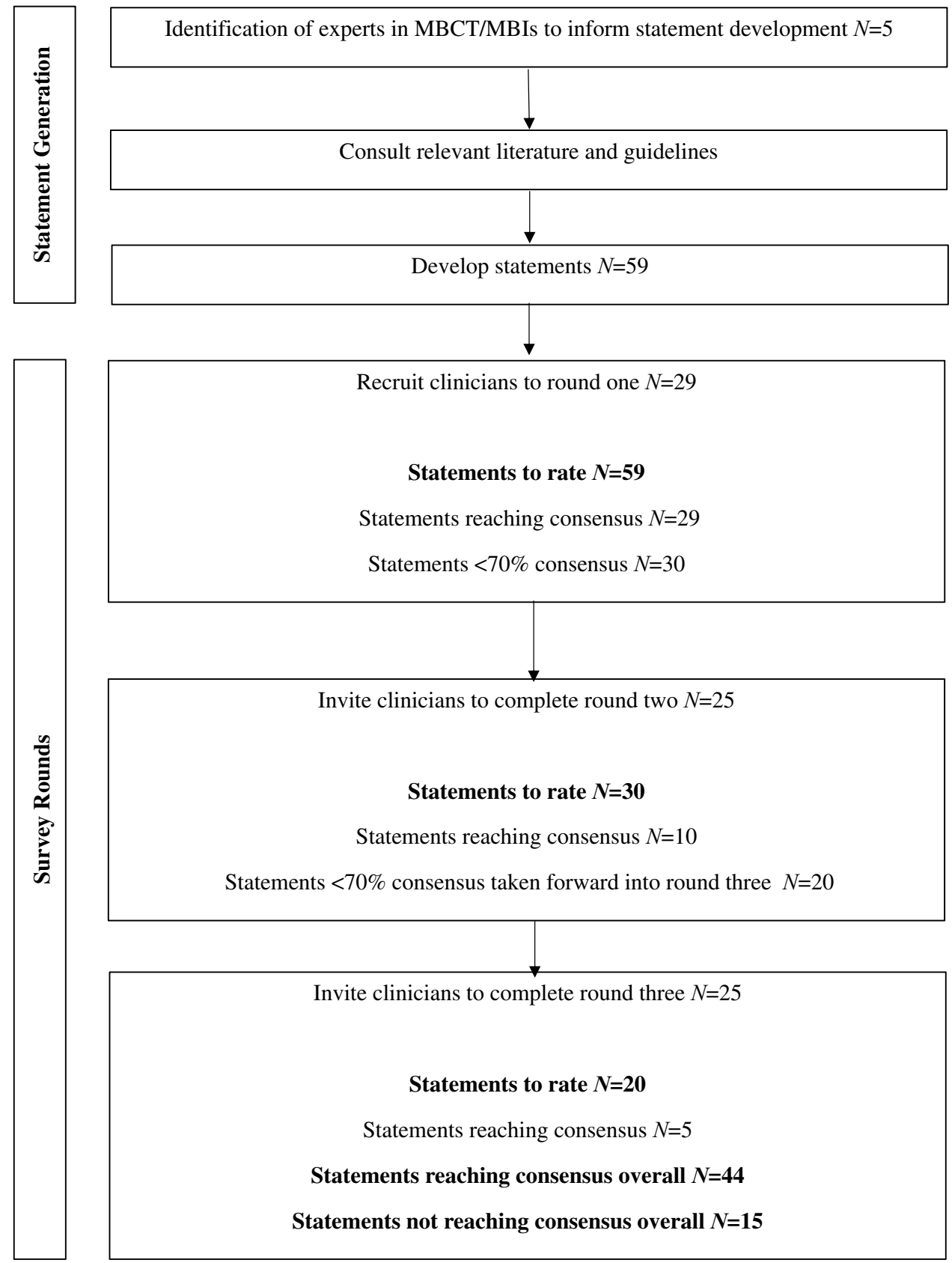

\section{Stage One. Statement Generation}

\section{Participants}

Participants were recruited through social media adverts and emails to specific mindfulness-based organisations, charities, and universities (Supplementary Material Table 1 includes details).

\section{Inclusion and Exclusion Criteria}

Participants had extensive experience (e.g., at least 5 years and/or had delivered at least five MBCT/MBI courses) with self-reported 'good knowledge' of delivering MBCT/MBIs in accordance with GPG (Crane 2011). Participants did not need to be currently or have previously worked in the NHS, nor be qualified as a 'clinical practitioner' as their expertise 
was either within MBCT and/or MBIs. A broad criterion around either MBCT or MBIs was adopted to allow for a range of relevant expertise for developing a wide pool of possible statements. Five participants were recruited; all had between 10 and $20+$ years of personal mindfulness meditation experience and undertaken recognised mindfulnessbased teacher training courses at the UK-based universities.

\section{Procedure}

Following initial email contact, participants were emailed the participant information sheet and asked to sign an online consent form if interested. An audio-recorded telephone interview was scheduled, lasting up to $30 \mathrm{~min}$, and followed an interview guide with conversation prompts (Supplementary Material S2). Further information was gathered to supplement the interviews using a literature review of additional sources including the evidence-base for MBCT/MBIs, GPG for delivery of MBIs (Crane 2011), and NICE guidelines for depression (2017; see Supplementary Material Table 2).

\section{Analyses}

Audio recordings were transcribed, uploaded into NVivo 12 (QSR International, 1999) for coding and generation of themes. Themes were combined with the literature review to develop a range of statements. Revisions to the statements were made within the research team, and two external, nonmindfulness-based researchers gave feedback on all statements; both researchers found the statements feasible, understandable, and timely to rate. Fifty-nine statements were taken forward into stage two (Supplementary Material S3.).

\section{Stage Two. Survey Rating Rounds}

\section{Participants}

Participants were recruited using purposive and snowball sampling methods targeted towards a range of outlets including special interest mindfulness groups and organisations, social media, UK-based doctorate in clinical psychology courses, the psychological professions network, and the university announcement service (Supplementary Material S4 includes details). Some researchers recommend between 10 and 50 participants, whereas others suggest 20 participants is sufficient for Delphi studies (Hasson et al., 2000; Turoff $\&$ Linstone, 1975). We aimed to recruit 24 participants, accounting for potential dropout between rounds (estimated retention rate between 76 and $91 \%$, based on Hall et al., 2018).

\section{Inclusion and Exclusion Criteria}

Participants were either qualified or in training as a clinical psychologist, psychiatrist, CBT therapist, psychological wellbeing practitioner, counsellor, psychotherapist, or mental health nurse. Participants were either currently or had recently worked within the NHS, third sector, or private sector (at least within the last 5 years). Participants needed to have delivered either MBCT or a related MBI either to groups or in a one-to-one capacity within any clinical service.

\section{Design}

For each round, statements were compiled into an online survey (Select Survey) hosted by the university. Participants rated each statement on a five-point Likert scale, dependent on the type of statement: either a rating of importance (' $1=$ completely unimportant', ' $2=$ somewhat unimportant', ' $3=$ neither important or unimportant', ' $4=$ somewhat important', ' $5=$ very important') or to rate their agreement (' $1=$ strongly disagree', ' $2=$ disagree', ' $3=$ neither agree nor disagree', ' $4=$ agree', ' $5=$ strongly agree'). A total of three rounds were chosen to provide a balance between the risk of insufficient data and participant fatigue (Green et al., 1999; Hasson et al., 2000).

\section{Procedure}

Once participants made contact, they were emailed the participant information sheet and gave informed consent at the start of the survey. At each round, participants were emailed up to three times (including reminders) with survey links. Demographics regarding age, gender, profession, service, experience with MBCT, and mindfulness meditation experience were obtained. Optional comments were invited after each statement. In each of rounds two and three, participants were provided with results from the previous round and were asked to re-rate all of the statements which did not reach the consensus of at least $70 \%$. Each round remained open for approximately 1 month (or until all responses had been gathered), with approximately one additional month in-between rounds.

\section{Analyses}

We followed the analysis procedures outlined in Langlands et al. (2008), with slight modifications to the percentage at which consensus was reached (70\%), adjusted to reflect a strong majority consensus and varying consensus levels within the literature (50-97\% in Diamond et al., 2014; 70\% in Veugelers et al., 2020). Full consensus for each statement (100\%) was not required (Hsu \& Sandford, 2007). The level 
of consensus was calculated for each statement, and statements reaching the consensus of at least $70 \%$ (across combined rating responses of either 1 and 2 or 4 and 5) were not taken into the next round.

\section{Results}

\section{Demographics}

Table 1 displays the demographics. Briefly, 29 clinicians took part in round one, with a mean age of 45.38 years

Table 1 Baseline demographics

\begin{tabular}{|c|c|}
\hline & $N=29$ \\
\hline Age & $M=45.38(\mathrm{SD}=12.21)$ \\
\hline Gender $\left(\%\right.$ female $\left.{ }^{a}\right)$ & 62.1 \\
\hline Length of time in current service (years) & $M=7.46(\mathrm{SD}=6.04)$ \\
\hline \multicolumn{2}{|l|}{ Job title } \\
\hline CBT therapist & $N=7 ; 24.1 \%$ \\
\hline Clinical psychologist & $N=6 ; 20.7 \%$ \\
\hline Service lead & $N=4 ; 13.8 \%$ \\
\hline Trainee clinical psychologist & $N=3 ; 10.3 \%$ \\
\hline High intensity therapist & $N=2 ; 6.9 \%$ \\
\hline Psychological wellbeing practitioner & $N=2 ; 6.9 \%$ \\
\hline Psychotherapist & $N=2 ; 6.9 \%$ \\
\hline Assistant psychologist & $N=1 ; 3.4 \%$ \\
\hline MBCT teacher (as a sole profession) & $N=1 ; 3.4 \%$ \\
\hline Occupational therapist & $N=1 ; 3.4 \%$ \\
\hline \multicolumn{2}{|l|}{ Sector } \\
\hline NHS & $N=25 ; 86.2 \%$ \\
\hline Private & $N=2 ; 6.9 \%$ \\
\hline NHS and private & $N=1 ; 3.4 \%$ \\
\hline Charity & $N=1 ; 3.4 \%$ \\
\hline \multicolumn{2}{|l|}{ Service Location } \\
\hline North West England & $N=15 ; 51.7 \%$ \\
\hline Yorkshire & $N=4 ; 13.8 \%$ \\
\hline North East England & $N=3 ; 10.3 \%$ \\
\hline Wales & $N=2 ; 6.9 \%$ \\
\hline Midlands & $N=2 ; 6.9 \%$ \\
\hline East/South East England & $N=2 ; 6.9 \%$ \\
\hline Scotland & $N=1 ; 3.4 \%$ \\
\hline \multicolumn{2}{|l|}{ Teacher training } \\
\hline Completed & $N=21 ; 72.4 \%$ \\
\hline Considering training & $N=4 ; 13.8 \%$ \\
\hline Not in training & $N=3 ; 10.3 \%$ \\
\hline In training & $N=1 ; 3.4 \%$ \\
\hline \multicolumn{2}{|l|}{ Mindfulness experience } \\
\hline Personal practice $(\%)$ & $N=27 ; 93.1 \%$ \\
\hline Length of practice (years) & $M=12.67(\mathrm{SD}=12.57)$ \\
\hline
\end{tabular}

${ }^{\mathrm{a}}$ All participants identified as either female or male.
$(\mathrm{SD}=12.21)$ and $62.1 \%$ identifying as female. Most clinicians were employed as either a CBT therapist, clinical psychologist (qualified or in training), or service lead. The majority were delivering MBCT in the NHS (86.2\%), with over 50\% delivering MBCT in North West England. The majority (89.7\%) based their answers on their experience of teaching MBCT via groups, $6.9 \%$ via one-to-one, and 3.4\% via telephone. The majority maintained a personal mindfulness practice $(93.1 \%)$, with most having either completed or currently in MBCT teacher training (combined 75.8\%).

\section{Survey Rounds}

Twenty-nine clinicians completed round one, with 25 subsequently completing both of rounds 2 and 3 (14\% attrition). A move towards consensus was gradual, with 29/59 statements reaching at least $70 \%$ consensus in round one, a further 10 statements in round two, and a further five statements in round three; a total of $15 / 59$ statements did not reach consensus. Tables 2 and 3 display the results from all rounds for statements reaching and not reaching consensus, respectively, followed by a narrative description. Of note, for 18 statements which concerned the population that MBCT could be delivered to, we offered a 'don't know' option. This option was rarely used but for completeness. Supplementary material S5 shows these results.

\section{Access}

Four of seven statements reached a consensus in round one. Specifically, clinicians agreed with statements related to the following: preparation and ease of access to MBCT, agreeing with the importance of providing clients with a thorough assessment; comprehensive discussions of the risks, difficulties, and expectations prior to MBCT; and ensuring that MBCT is accessible across a range of services. Three statements did not reach a consensus; these concerned the accessibility of MBCT for all clients, the level of commitment required, and whether MBCT holds a stigma or lacks credibility. Although not reaching a consensus, these three statements were rated towards a direction of disagreement. Firstly, clinicians reflected on the importance of delivering MBCT to clients for whom there is an evidence-base ("it should be offered if there is an evidence base for it being helpful'), as well as a consideration of individual needs and 'suitability of the client' before offering MBCT. Secondly, reflections on the commitment required generated different views. These included highlighting the individual client variation ('for some people it is (too long), for others it is too little'); population ('it depends on the client group'); and an acknowledgement that although MBCT can seem like a big commitment, the evidence-base suggests that optimum benefit comes from attendance, engagement, and 
Table 2 Statements with consensus

\begin{tabular}{|c|c|c|}
\hline $\begin{array}{l}\text { Round } 1 \\
\text { percent- } \\
\text { age }\end{array}$ & $\begin{array}{l}\text { Round } 2 \\
\text { percent- } \\
\text { age }\end{array}$ & $\begin{array}{l}\text { Round } 3 \\
\text { percent- } \\
\text { age }\end{array}$ \\
\hline$N=29$ & $N=25$ & $N=25$ \\
\hline
\end{tabular}

Consensus towards 'strongly disagree/disagree'

Delivery-population

Clients experiencing symptoms in line with a 'crisis' or acute illness

Adaptations-course structure

Delivering MBCT as the full 8-week programme is not feasible in clinical settings

It is acceptable to shorten individual sessions/course lengths to accommodate service needs

65.52

84.00

Adaptations - types

There should be fewer home practice requirements

65.52

76.00

Consensus towards 'strongly agree/agree'

Preparation and ease of access

The potential risks and difficulties of MBCT are fully discussed with clients before MBCT starts ${ }^{\mathrm{a}}$

MBCT should be more widely available across services

A comprehensive assessment with each client should be carried out prior to starting MBCT $^{\text {a }}$

92.86

MBCT should be accessible across all styles of services

89.29

Delivery-Population

Clients

...experiencing symptoms in line with anxiety

...who are currently well but who experience recurrent depression

96.55

...with 'long-term physical health conditions' (e.g., cancer)

93.10

...experiencing symptoms in line with current depression

89.66

...experiencing symptoms in line with a diagnosis of 'borderline personality disorder' $\quad 58.62$

...with histories of trauma

79.31

...experiencing multiple comorbid difficulties

48.28

...who are experiencing a significant life event

55.17

MBCT should be adapted to work with people with a history of trauma (e.g., trauma-sensitive mindfulness)

93.10

With careful adaptations, anybody can take part in it

62.07

80.00

Delivery-risks

Negative effects of meditation can occur if the meditation is not guided safely or held wisely by the teacher Negative effects of meditation can occur irrespective of the teacher's delivery and holding of the group

It is potentially harmful if MBCT courses do not have an underlying evidence-based foundation

89.66

82.76

58.62

68.00

Delivery-GPG

The Good Practice Guidelines (GPG) for MBCT teachers should be adhered to when delivering MBCT courses

It is more important that the teacher has sufficient experience delivering MBCT than if they are strictly adhering to GPG

93.10

44.83

68.00

Delivery-teacher training and personal practice

Before teaching MBCT, teachers should participate in an MBCT or similar mindfulness-based course themselves

Staff cannot effectively teach MBCT if they do not have personal experience of mindfulness meditation

Teaching MBCT should be based on an experiential understanding whereby teachers are familiar with the language/territory of mindfulness

Staff teaching MBCT should have access to initial training courses as part of their job role

Staff teaching MBCT should have access to ongoing supervision and training as part of their job role

Without sufficient training in delivering MBCT, harm could be done

MBCT teacher training is not taken as seriously compared to other therapies

68.00

76.00

Mindfulness-informed therapy is more accessible than delivering a full MBCT course

Delivery-services

MBCT needs to be properly resourced with sufficient numbers of trained teachers
96.55

86.21

44.83

55.17

96.55

96.55

96.55

96.55 
Table 2 (continued)

\begin{tabular}{|c|c|c|c|}
\hline & $\begin{array}{l}\text { Round } 1 \\
\text { percent- } \\
\text { age } \\
N=29\end{array}$ & $\begin{array}{l}\text { Round } 2 \\
\text { percent- } \\
\text { age } \\
N=25\end{array}$ & $\begin{array}{l}\text { Round } 3 \\
\text { percent- } \\
\text { age } \\
N=25\end{array}$ \\
\hline MBCT cannot thrive in a service without adequate support from managers/service leads & 96.30 & & \\
\hline Services need to have a better understanding of MBCT to be able to offer it effectively to clients & 93.10 & & \\
\hline \multicolumn{4}{|l|}{ Delivery-resources } \\
\hline Sufficient resources to deliver MBCT should be provided by the service & 100.00 & & \\
\hline $\begin{array}{l}\text { The lack of sufficient funding for MBCT puts clients at risk with MBCT being delivered in a non- } \\
\text { evidence-based manner }\end{array}$ & 65.52 & 84.00 & \\
\hline \multicolumn{4}{|l|}{ Adaptations-course structure } \\
\hline $\begin{array}{l}\text { The MBCT curriculum (e.g., duration, content) can be adapted and tailored to the needs of the group/ } \\
\text { individual }\end{array}$ & 89.66 & & \\
\hline It is acceptable to deliver MBCT either in a group or one-to-one format & 86.21 & & \\
\hline It is acceptable to shorten individual sessions or the course length to accommodate client needs & 51.72 & 80.00 & \\
\hline It is acceptable to teach elements of the MBCT curriculum rather than the full MBCT curriculum & 62.07 & 76.00 & \\
\hline \multicolumn{4}{|l|}{ Adaptations-types } \\
\hline Adaptations should reflect the needs of clients but also be in line with the core philosophy of MBCT & 93.10 & & \\
\hline $\begin{array}{l}\text { Adaptations to MBCT must ensure that they are in line with the underlying evidence base for the } \\
\text { population }\end{array}$ & 86.21 & & \\
\hline $\begin{array}{l}\text { If a full MBCT course cannot be delivered, then adaptations should be as close to the original pro- } \\
\text { gramme as possible }\end{array}$ & 82.76 & & \\
\hline Shorter meditation practices during MBCT may help increase participant engagement & 65.52 & 76.00 & \\
\hline
\end{tabular}

a Ratings for these items were 'completely important/somewhat important'.

$G P G$, Good Practice Guidelines.

practice. Thirdly, with regards to stigma and/or a potential lack of credibility around MBCT, some clinicians wondered whether education around the misconceptions of MBCT would help ('MBCT is well researched and has a good evidence-base...ensuring that clients are aware of this might reduce such beliefs'). Some wondered whether MBCT attracts teachers from particular backgrounds which may add to cultural divides ('MBCT attracts a lot of white middleclass individuals'), whilst others were unaware of any stigma or lack of credibility.

\section{Delivery}

\section{Population}

Eleven of eighteen statements reached consensus. Clinicians agreed that MBCT could be delivered to people with either recurrent or current depression, anxiety, comorbidities, histories of trauma, and long-term physical health conditions. For some populations, the consensus took longer to reach. This was reflected in the comments related to uncertainty around the lack of evidence for a specific condition (e.g., people with diagnoses of 'Borderline Personality Disorder'); that adaptations may be necessary to account for risk, safety, and timing of MBCT (e.g., MBCT could be too 'heavy'); and consideration of trauma-sensitive adaptations (e.g., for clients experiencing significant life events or in acute crisis).

Seven statements did not reach a consensus. These statements included considerations of whether anybody can take part, and specific population 'groups' including clients experiencing dissociation/dissociative symptoms, current suicidal ideation, diagnoses of bipolar, psychosis, eating disorders, or substance abuse/dependence. Largely, clinicians did not agree in either direction, and the comments were replicated across most statements through emphasising a need for careful decision-making regarding the delivery of MBCT. Firstly, clinicians commented on the need to ensure that relevant qualifications or experience with both MBCT and the client group were in place (the 'training of (the) practitioner needs to be considered'). Secondly, clinicians reflected that they were either unfamiliar or unaware of an evidence-base for that condition; one clinician reflected that any MBCT intervention 'if offered in the NHS, needs to be evidence-based'. Thirdly, clinicians reflected on the need for person-centred approaches whilst acknowledging the severity of a client's current difficulties, additional support or ongoing therapy, and the need for a thorough formulation, care plan, and risk assessment ('risks and expectations need to be managed'). 
Table 3 Statements without consensus

\begin{tabular}{|c|c|c|c|}
\hline & $\begin{array}{l}\text { Round } 1 \\
\text { percent- } \\
\text { age } \\
N=29\end{array}$ & $\begin{array}{l}\text { Round } 2 \\
\text { percent- } \\
\text { age } \\
N=25\end{array}$ & $\begin{array}{l}\text { Round } 3 \\
\text { percent- } \\
\text { age } \\
N=25\end{array}$ \\
\hline \multicolumn{4}{|l|}{ Consensus towards 'strongly disagree/disagree' } \\
\hline \multicolumn{4}{|l|}{ Access—ease } \\
\hline MBCT in its standard format is too much of a commitment & 50.00 & 48.00 & 60.00 \\
\hline $\begin{array}{l}\text { MBCT should be accessible for all clients who want to take part in it, irrespective of difficulties or } \\
\text { service context }\end{array}$ & 35.71 & 44.00 & 56.00 \\
\hline MBCT carries a stigma; clients and/or services may perceive it as 'airy fairy'/lacking credibility & 46.43 & 64.00 & 56.00 \\
\hline \multicolumn{4}{|l|}{ Delivery-population } \\
\hline Anybody who wants to take part in it & 34.48 & 44.00 & 52.00 \\
\hline Clients experiencing dissociative symptoms/dissociation & 37.93 & 52.00 & 52.00 \\
\hline \multicolumn{4}{|l|}{ Delivery—risks } \\
\hline $\begin{array}{l}\text { MBCT should be delivered to clients only when there is a sound, underlying theoretical rationale for } \\
\text { doing so }\end{array}$ & 31.03 & 28.00 & 48.00 \\
\hline \multicolumn{4}{|l|}{ Consensus towards 'strongly agree/agree' } \\
\hline \multicolumn{4}{|l|}{ Delivery-population } \\
\hline \multicolumn{4}{|l|}{ Clients... } \\
\hline ...experiencing symptoms in line with an eating disorder & 48.28 & 48.00 & 64.00 \\
\hline ...with current suicidal ideation & 55.17 & 52.00 & 64.00 \\
\hline ...experiencing symptoms in line with a bipolar diagnosis & 58.62 & 68.00 & 64.00 \\
\hline ...experiencing symptoms in line with psychosis & 41.38 & 44.00 & 52.00 \\
\hline ...with difficulties with alcohol or substance use/dependence & 55.17 & 44.00 & 48.00 \\
\hline \multicolumn{4}{|l|}{ Delivery_population risks } \\
\hline The potential risks or side effects of MBCT are often understated & 37.93 & 48.00 & 60.00 \\
\hline \multicolumn{4}{|l|}{ Delivery—services } \\
\hline Staff are teaching MBCT without sufficient training because of service restrictions & 51.72 & 48.00 & 56.00 \\
\hline Services who cannot properly fund MBCT should not offer it at all & 27.59 & 24.00 & 24.00 \\
\hline \multicolumn{4}{|l|}{ Adaptations-types } \\
\hline Practices could be graded by intensity (less intense practices could be offered first) & 62.07 & 64.00 & 60.00 \\
\hline
\end{tabular}

Supplementary material Table 6 includes individual statement ratings to show the spread of responses.

\section{Risks}

Three of five statements reached a consensus. One statement related to the potential for harm if MBCT is not taught from its evidence-based foundation. Two statements prompted clinicians to reflect on the 'cause' of potential harm, either through the presence of or a lack of teacher guidance or holding of the group. Interestingly, clinicians agreed with both statements, suggesting that harm can arise through different routes ('harm doesn't come from theory, it comes from insensitivity' or from the 'intentions of the teacher'). Clinicians described giving clients a choice and the ability to 'opt out' of practices, as well as clarifying expectations around MBCT. Importantly, the potential for harm and distress can be interpreted differently and, of course, can be a natural, expected outcome of meditation ('clients may experience distress in relation to internal experiences'), but clinicians emphasised the importance of the teacher in being able to recognise, support, and manage these risks.

Two statements did not reach a consensus. First, clinicians did not reach a consensus around whether MBCT should be delivered to clients only when there is a sound underlying theoretical rationale. Clinicians commented that a flexible approach to the delivery of MBCT may be required ('I agree that we should recognise the research basis...but without being excessively purist'). Second, with regards to whether potential side effects are understated, clinicians rated towards 'strongly agree/agree' with reflections that side effects are a risk across all therapies, not just MBCT. Clinicians highlighted the need for more research and in ensuring that everything is invitational. 


\section{Good Practice Guidelines (GPG)}

Two statements reached a consensus with the agreement that the GPG should be adhered to, alongside a recognition that it is somewhat rigid to always strictly adhere to the GPG. Clinicians described how experience with MBCT and adherence to GPG were both important and reflected that 'there isn't a trade off' as the two complement each other whereby 'any teacher with sufficient experience is likely to be working to the GPGs regardless'. Clinicians reflected on the importance of a 'careful balance between the two', with the recognition that a flexible approach to MBCT teaching and adherence to GPG may be needed at times, particularly if some of the requirements cannot always be met (e.g., attendance at week-long residential retreats).

\section{Teacher Training and Personal Practice}

All eight statements reached a consensus towards agreement. Six statements reached consensus by round one whereby clinicians agreed that to teach MBCT effectively: Teachers should have an experiential understanding of mindfulness through personal participation in MBCT/MBI courses; that access to both training and supervision should be available; and that without sufficient training, there is potential for harm. There was strong agreement towards an experiential understanding of mindfulness-based practices affording teachers a deeper, embodied understanding of MBCT (it is 'vital to understand the process from the inside out'). Some clinicians questioned how MBCT can be taught effectively without personal meditation experience ('the base in "mindfulness-based" comes from within, without it, it isn't teaching'). There was strong consensus around access to training and supervision whereby one clinician commented: 'no supervision? No groups!'. The complexities around the potential for harm towards both participants and the integrity of MBCT as an intervention were acknowledged. Whilst one clinician wondered whether teaching MBCT without previous mindfulness experience could 'damage the reputation of mindfulness', another wondered whether harm could arise either to participants or the reputation of MBCT even when clinicians have sufficient training.

Two statements gained consensus by later rounds and prompted mixed comments. Whilst clinicians agreed that mindfulness-informed therapy is more accessible (e.g., applying mindfulness-based principles in therapeutic work, as opposed to a formal MBCT/MBI course), some wondered whether this risks missing key MBCT teachings and 'won't embed the key ideas that repeated practice and teaching will'. Clinicians agreed that MBCT may be taken less seriously than other therapies, with some wondering whether mindfulness is 'seen as the easy route into professional practice'. Others questioned why MBCT is not offered more widely within training courses (e.g., doctorate in clinical psychology). Some clinicians reflected that there may be negative top-down perceptions from service managers who regard MBCT less seriously than other therapies.

\section{Services}

Three of five statements reached a consensus. These statements reached a consensus in round one, and clinicians agreed with the importance of needing trained MBCT teachers in services, alongside supportive managers. Some clinicians commented on their experience of having delivered mindfulness-based classes for staff who were then able to better understand $\mathrm{MBCT}$ and subsequently refer clients more effectively. Whilst agreement was high, some commented that a properly resourced service for delivering MBCT is 'an ideal and not always practically possible' when balancing all resource demands across all therapies in services.

The consensus was not reached for two statements which, firstly, proposed that services should not deliver MBCT if they cannot adequately fund it and, secondly, that as a result of service restrictions, staff teach MBCT without sufficient training. Both statements tended to be rated as 'neither agree nor disagree' with no clear direction towards consensus and prompted mixed comments. For the first statement, some clinicians wondered whether 'underfunded MBCT is better than no MBCT'. However, others commented that MBCT should be properly funded and questioned 'if there is insufficient funding to offer it properly, is it even ethical to do so?' For the second statement, no consensus was reached and clinicians commented that they were unsure how to rate as they were unaware of staff teaching without training.

\section{Resources}

Both statements reached a consensus. Firstly, clinicians agreed that services should provide sufficient resources, but with an acknowledgement that some resources are now easier to source (e.g., access to online instead of CD-based audio). The second statement (whether a lack of resources puts clients at risk of a non-evidence-based MBCT) reached consensus by round two and elicited fewer but mixed comments. One clinician commented that this becomes an 'ethical issue for teachers' who should, if aware that there is insufficient funding and resources, raise it as an issue and subsequently not teach MBCT. Another clinician commented on their experience of making changes to MBCT because of service restrictions. This clinician commented on how they felt that the resultant course was not as effective (they made 'major changes to...meet service demands and (I) know they have been less effective'). 


\section{Adaptations}

\section{Course Structure}

All six statements reached consensus, albeit with ratings in different directions. Firstly, clinicians disagreed with the statement which suggested that delivering MBCT as a full 8 -week programme is not feasible, but acknowledged that adaptations may be needed (e.g., in acute settings). Secondly, clinicians disagreed that it is acceptable to shorten sessions or course length to accommodate service needs describing fears that MBCT would 'lose it's integrity'; such decisions should 'be led by the needs of that population and not service restrictions'.

For the remaining four statements, clinicians agreed that it is acceptable to deliver MBCT in groups or one-to-one settings, to teach only elements of the MBCT course, and to adapt and/or tailor MBCT or MBCT session duration or length to meet individual client needs. Most comments centred around ensuring all adaptations reflect a client-centred approach, particularly as 'each group has different needs'. One clinician commented that learning to sit for longer periods of time is integral to the learning and that to shorten MBCT would work 'against the principles of mindfulness'; others reflected that there is a "need (for) more evidence on the effectiveness of shorter programmes'. There was some reticence around adaptations through only teaching elements of MBCT with the recognition that 'MBCT in its own right is comprehensive'. However, clients should be made aware that they are not receiving full MBCT ('don't call it MBCT... it could be an introduction to mindfulness').

\section{Types of Adaptations}

Five of six statements reached a consensus: Clinicians agreed that shorter practices could increase engagement and that any adaptations should reflect the client's needs, the core philosophy of MBCT, and should not deviate significantly from the evidence-base. Clinicians reflected that this is 'a very carefully considered balancing act'. Clinicians agreed that whilst shorter practices may help to increase engagement, they disagreed that there should be fewer home practice requirements. Instead, clinicians reflected that home practice is a 'vital element of MBCT'; by reducing these requirements, MBCT could differ 'so much that it bears little resemblance and has no valid research-base'. Overall, clinicians recognised the complexity of making decisions around adaptations which could be 'more flexible and reasonable depending on demands and stressors in an individual's life'.

No consensus was reached for whether practices could be graded by intensity (e.g., offering less intense practices first such as grounding exercises). This statement elicited similar views around consideration of client needs whilst reflecting the evidence-base. One clinician reflected on how the learning in MBCT arises through those practices that may be harder or that people 'struggle' with, highlighting the importance of maintaining these. However, clinicians also recognised that some adaptations may be dependent on the client group.

\section{Discussion}

We aimed to establish consensus amongst clinicians with expertise in MBCT in clinical settings regarding their views on what should be best practice in terms of access to, delivery of, and adaptations to MBCT. Following an initial consultation period and review of the literature, expert clinicians rated 59 statements across three rating rounds.

Overall, clinicians reached a consensus on 44 statements concerning the importance of ensuring sufficient preparation for and ease of accessing MBCT, careful consideration around who might benefit from MBCT with regards to the evidence-base, consideration of potential risks, adherence to GPG, and the importance of an experiential understanding of mindfulness developed through personal meditation practice. Furthermore, clinicians agreed with statements concerning sufficient initial and ongoing training in MBCT, adherence to MBCT teacher guidelines, support from and sufficient resources within services, and carefully considered adaptations. Overall, clinicians agreed with the core, underlying aspects of MBCT in clinical settings as reflected in the GPG and wider evidence-base. Clinicians agreed with statements reflecting the essential and the flexible components required in MBIs (Crane et al., 2016). These included the emphasis on the underlying evidence-base and core philosophy of MBCT, teacher embodiment of mindfulness-based qualities, engagement in ongoing training, and adherence to guidelines, whilst staying attuned to individual client needs, making careful adaptations as required.

Fifteen statements did not reach a consensus. In general, and reflected in many of the comments, the non-consensus generally reflected either mixed opinions around the statement or an unfamiliarity with the evidence-base. At times, the non-consensus was reflective of the complexities involved in making decisions around MBCT in clinical settings. The consensus was not reached on statements related to questions around the level of commitment required for MBCT, potential credibility and stigma surrounding MBCT, and the evidence-base and application of MBCT for certain populations. Furthermore, the consensus was not reached on statements around whether the risks of MBCT are understated, the impact of service restrictions on the delivery of MBCT, and decisions around adaptations to specific practices. 
The majority of comments reflected on the importance of the underlying evidence-base and recognised the complexity involved in decision-making. Clinicians agreed with the delivery of MBCT for populations with the strongest evidence base; specifically, for people with recurrent or current depression (Goldberg et al., 2019; Kuyken et al., 2016; Mackenzie et al., 2018), histories of trauma (Williams et al., 2014), and anxiety and long-term physical health conditions, although there is more evidence for mindfulness-based stress reduction (MBSR; Kabat-Zinn, 1990) for the latter two populations (Chiesa \& Serretti, 2011; Compen et al., 2018; Ninomiya et al., 2020; Rodrigues et al., 2017; Strege et al., 2018). There were some populations for whom clinicians reflected on either their unfamiliarity with or the lack of available evidence-base. Overall, more research is needed around the efficacy of MBCT for populations including people with symptoms of dissociation, bipolar, current suicidal ideation, psychosis, eating disorders, and substance abuse/ dependence.

Whilst of course no therapy is risk-free, the lack of evidence-base led clinicians to exert caution around MBCT for certain population groups (Jonsson et al., 2014). There are many unknowns regarding the potential harm from MBCT, and somewhat in line with our clinicians' ratings, others have cautioned against MBIs for people with current suicidal ideation, psychosis, and substance dependence (Kuyken et al., 2012; Santorelli et al., 2017). Two studies have suggested that the most common harmful experiences arising from MBCT are (new-onset of) depression and anxiety as well as depersonalisation and reexperiencing of trauma, and psychotic experiences; although these studies either included non-clinical participants or participants taking part in different MBIs or more intense meditations (Baer et al., 2021; Farias et al., 2020). Whilst unpleasant experiences are an expected natural consequence of taking part in meditation, it remains that there are unknowns regarding the potential for longer-lasting harm from MBCT in clinical populations. Further research around the potential for harm from MBCT is warranted.

Repeated across a number of statements and comments, clinicians reflected on the importance of the delicate balance in maintaining a flexible client-centred approach. This included prioritisation of the individual needs, expectations, and safety of the client, whilst staying close to the evidence-base, GPG, and the core underlying philosophy of MBCT. This is especially important given the potential for busy, overstretched services to require changes to MBCT in light of restricted funding or resources. Maintaining a client-centred approach is reflected in the wider literature whereby all mindfulness-based practices are invitational alongside a core understanding of humility whereby the client is the expert of their individual experience (Crane et al., 2016; Kabat-Zinn, 1990; Segal et al.,
2013). Others have also noted the delicate balance between increasing access whilst maintaining the integrity of MBCT, alongside the importance of ensuring the client is fully aware of the potential risks, the presence of support should difficult experiences arise, and that clients have the choice as to whether they continue participation in MBCT (Farias \& Wikholm, 2016; Williams \& Birtwell, 2018). Our results highlight important considerations for MBCT teachers in clinical settings around the importance of a flexible, client-centred approach. Such an approach would prioritise client needs, expectations, and safety, whilst ensuring the evidence-base, GPG, and the core underlying philosophy of MBCT are followed. Specifically, the GPG could be amended to explicitly emphasise this delicate but complex balance between remaining client-centred whilst adhering to the evidence-base (e.g., through including a statement encouraging MBCT teachers to incorporate the above factors into their decision-making around MBCT access, delivery, and adaptations).

Another repeated theme reflected the need for ensuring honesty and transparency through discussions with clients and services. Specifically, this referred to ensuring transparency around expectations, misconceptions, potential for harm and/or distress, the value of and potential learning derived from engaging in longer practices and in home practice, ensuring an invitational stance, and adaptations. Ensuring clients are aware of and have the opportunity to address any misconceptions fits with the wider literature. Specifically, others have reported how MBCT participants had either expected a 'cure' or that their misconceptions around MBCT later impacted on their ability to either maintain a mindfulness practice or fully benefit from MBCT (Bihari \& Mullan, 2014; Finucane \& Mercer, 2006; Mason \& Hargreaves, 2001). Additionally, ensuring transparency is important given the popularity of MBCT and the recent push to increase access to MBCT in the NHS (Mindfulness All Party Parliamentary Group, 2015; NHS England \& Health Education England, 2016). Finally, it is important to ensure clinicians and services endeavour to remain transparent about what MBCT is being delivered. This is particularly important in light of the report from Rycroft-Malone et al., (;2017, 2019) on the 'patchy' delivery of MBCT, adaptations in response to target-driven and financial pressures, and limited access to training and supervision. Therefore, services could ensure careful consideration of adequate funding (for training, supervision, and sufficient resources) and consider the ethical considerations if the above are not available. In addition to discussing and educating clients about potential misconceptions or their expectations about MBCT, increased education for service managers and leads may help in ensuring an increased understanding of MBCT and a more effective referral process. 


\section{Limitations and Future Research}

Our recruitment of a range of clinicians from different specialties and training levels adds a broader perspective to our findings. However, it should be noted that over $50 \%$ of our sample consisted of CBT therapists, clinical psychologists, or service leads, but this may reflect the likely demographics of who predominantly teaches MBCT in clinical settings. Although efforts were made to recruit psychiatrists, none responded to the adverts. Not all of the clinicians provided qualitative comments for every statement, making it difficult to know whether all comments reflected everyone's views, although of course the agreement rating helps reassure us of clinicians' views regarding each statement. It should also be noted that as we recruited expert clinicians with a keen professional, and possibly personal, interest and expertise in MBCT, this will have inevitably affected their ratings; whether the views of clinicians would fit with what clients want and value from MBCT is unknown and warrants further research. Finally, although the majority of the clinicians surveyed had undergone MBCT training and maintained a personal mindfulness meditation practice, we recognise that $24 \%$ and $7 \%$ respectively had not. As part of our study criteria, we did not require clinicians to have undergone specific training in MBCT or to hold a current mindfulness practice. This suggests that some of our samples may not have delivered MBCT in line with the GPG. On reflection, further questions around clinicians' MBCT training decisions, whether they previously held a personal mindfulness practice, and whether clinicians were co-facilitating MBCT groups with another clinician who had undergone the required training would help to better understand our sample.

Twenty-nine clinicians rated 59 statements regarding their views on what should be considered best practice in the access to, delivery of, and adaptations to MBCT in clinical settings. The majority of statements reached a consensus amongst clinicians, with 15 statements not reaching consensus either due to a lack of evidence-base, unfamiliarity, or uncertainty around complex decision-making processes. Our findings highlight a need for more research into both the efficacy of MBCT and the potential for harm in underresearched populations, and the importance of an awareness of the delicate balance between remaining both client-centred and in line with the evidence-base. Furthermore, our findings highlight the importance of transparency around misconceptions and/or expectations both before and during MBCT, and increased education about MBCT for service managers, and lead to enhance understanding and increase effective referral processes.

Supplementary Information The online version contains supplementary material available at https://doi.org/10.1007/s12671-021-01706-5.
Acknowledgements The authors would like to acknowledge and extend gratitude to all of the clinicians who took the time to participate in this study

Author Contribution KW designed and executed the study, analysed the data, and drafted and edited the.

manuscript. SH and PT supervised the design, study completion, and analysis, and all authors contributed to the drafting and editing of the manuscript. All authors have approved the final version of the manuscript for submission.

\section{Declarations}

Ethics Approval Ethical approval for both stages was given by The Psychology and Mental Health Division Panel at The University of Manchester.

Consent to Participate All participants gave written informed consent in line with the Declaration of Helsinki (World Medical Association, 2001).

Conflict of Interest The authors declare no competing interests.

Open Access This article is licensed under a Creative Commons Attribution 4.0 International License, which permits use, sharing, adaptation, distribution and reproduction in any medium or format, as long as you give appropriate credit to the original author(s) and the source, provide a link to the Creative Commons licence, and indicate if changes were made. The images or other third party material in this article are included in the article's Creative Commons licence, unless indicated otherwise in a credit line to the material. If material is not included in the article's Creative Commons licence and your intended use is not permitted by statutory regulation or exceeds the permitted use, you will need to obtain permission directly from the copyright holder. To view a copy of this licence, visit http://creativecommons.org/licenses/by/4.0/.

\section{References}

Baer, R., Crane, C., Miller, E., \& Kuyken, W. (2019). Doing no harm in mindfulness-based programs: Conceptual issues and empirical findings. Clinical Psychology Review, 71, 101-114. https://doi. org/10.1016/j.cpr.2019.01.001

Baer, R., Crane, C., Montero-Marin, J., Phillips, A., Taylor, L., Tickell, A., \& Kuyken, W. (2021). Frequency of self-reported unpleasant events and harm in a mindfulness-based program in two general population samples. Mindfulness, 12, 763-774. https://doi.org/10. 1007/s12671-020-01547-8

Bihari, J. L. N., \& Mullan, E. G. (2014). Relating mindfully: A qualitative exploration of changes in relationships through mindfulnessbased cognitive therapy. Mindfulness, 5(1), 46-59. https://doi.org/ 10.1007/s12671-012-0146-x

Boyd, J. E., Lanius, R. A., \& McKinnon, M. C. (2018). Mindfulnessbased treatments for posttraumatic stress disorder: A review of the treatment literature and neurobiological evidence. Journal of Psychiatry \& Neuroscience : JPN, 42(6), 7-25. https://doi.org/ 10.1503/jpn.170021

Britton, W. B. (2019). Can mindfulness be too much of a good thing? The value of a middle way. Current Opinion in Psychology, 28, 159-165. https://doi.org/10.1016/j.copsyc.2018.12.011

Chiesa, A., \& Serretti, A. (2011). Mindfulness based cognitive therapy for psychiatric disorders: A systematic review and meta-analysis. 
Psychiatry Research, 187(3), 441-453. https://doi.org/10.1016/j. psychres.2010.08.011

Compen, F., Bisseling, E., Schellekens, M., Donders, R., Carlson, L., van der Lee, M., \& Speckens, A. (2018). Face-to-face and internet-based mindfulness-based cognitive therapy compared with treatment as usual in reducing psychological distress in patients with cancer: A multicenter randomized controlled trial. Journal of Clinical Oncology, 36(23), 2413-2421. https://doi.org/10.1200/ JCO.2017.76.5669

Crane, R. S. (2011). The British Association of Mindfulness-based Approaches (BAMBA) UK Good Practice Guidelines for mindfulness-based teachers. Retrieved 26/01/2021, from https://bamba. org.uk/wp-content/uploads/2019/06/UK-MB-teacher-GPG-2015final-2.pdf

Crane, R. S., Brewer, J., Feldman, C., Kabat-Zinn, J., Santorelli, S., Williams, J. M. G., \& Kuyken, W. (2016). What defines mindfulness-based programs? The warp and the weft. Psychological Medicine, 47(6), 990-999. https://doi.org/10.1017/S003329171 6003317

Crane, R. S., \& Kuyken, W. (2013). The implementation of mindfulness-based cognitive therapy: Learning from the UK health service experience. Mindfulness, 4(3), 246-254. https://doi.org/ 10.1007/s12671-012-0121-6

de Meyrick, J. (2003). The Delphi method and health research. Health Education, 103(1), 7-16. https://doi.org/10.1108/0965428031 0459112

Diamond, I. R., Grant, R. C., Feldman, B. M., Pencharz, P. B., Ling, S. C., Moore, A. M., \& Wales, P. W. (2014). Defining consensus: A systematic review recommends methodologic criteria for reporting of Delphi studies. Journal of Clinical Epidemiology, 67(4), 401-409. https://doi.org/10.1016/j.jclinepi.2013.12.002

Dimidjian, S., \& Segal, Z. V. (2015). Prospects for a clinical science of mindfulness-based intervention. American Psychologist, 70(7), 593-620. https://doi.org/10.1037/a0039589

Farias, M., Maraldi, E., Wallenkampf, K. C., \& Lucchetti, G. (2020). Adverse events in meditation practices and meditation-based therapies: A systematic review. Acta Psychiatrica Scandinavica, 142(5), 374-393. https://doi.org/10.1111/acps.13225

Farias, M., \& Wikholm, C. (2016). Has the science of mindfulness lost its mind? Bjpsych Bulletin, 40(6), 329-332. https://doi.org/ 10.1192/pb.bp.116.053686

Finucane, A., \& Mercer, S. W. (2006). An exploratory mixed methods study of the acceptability and effectiveness mindfulness-based cognitive therapy for patients with active depression and anxiety in primary care. BMC Psychiatry, 6 (14). https://doi.org/10.1186/ 1471-244X-6-14

Goldberg, S. B., Tucker, R. P., Greene, P. A., Davidson, R. J., Kearney, D. J., \& Simpson, T. L. (2019). Mindfulness-based cognitive therapy for the treatment of current depressive symptoms: A metaanalysis. Cognitive Behaviour Therapy, 48(6), 445-462. https:// doi.org/10.1080/16506073.2018.1556330

Graham, L. F., \& Milne, D. L. (2003). Developing basic training programmes: A case study illustration using the Delphi method in clinical psychology. Clinical Psychology \& Psychotherapy, 10(1), 55-63. https://doi.org/10.1002/cpp.353

Green, B., Jones, M., Hughes, D., \& Williams, A. (1999). Applying the Delphi technique in a study of GPs' information requirements. Health and Social Care in the Community, 7(3), 198-205. https:// doi.org/10.1046/j.1365-2524.1999.00176.x

Hall, D. A., Smith, H., Heffernan, E., \& Fackrell, K. (2018). Recruiting and retaining participants in e-Delphi surveys for core outcome set development: evaluating the COMiT'ID study. PLoS ONE, 13(7). https://doi.org/10.1371/journal.pone.0201378

Hasson, F., Keeney, S., \& McKenna, H. (2000). Research guidelines for the Delphi survey technique. Journal of Advanced Nursing,
32(4), 1008-1015. https://doi.org/10.1046/j.1365-2648.2000. t01-1-01567.x

Hsu, C. and Sandford, B. (2007) The Delphi technique: making sense of consensus. Practical Assessment, Research \& Evaluation, 12, 1-8. https://scholarworks.umass.edu/pare/vol12/iss1/10

Jonsson, U., Alaie, I., Parling, T., \& Arnberg, F. K. (2014). Reporting of harms in randomized controlled trials of psychological interventions for mental and behavioral disorders: A review of current practice. Contemporary Clinical Trials, 38(1), 1-8. https://doi. org/10.1016/j.cct.2014.02.005

Kabat-Zinn, J. (1990). Full Catastrophe Living: Using the Wisdom of your Body and Mind to Face Stress, Pain and Illness. New York, NY: Delacorte.

Khodyakov, D., Grant, S., Denger, B., Kinnett, K., Martin, A., Peay, H., \& Coulter, I. (2020). Practical considerations in using online modified-Delphi approaches to engage patients and other stakeholders in clinical practice guidelinedevelopment. Patient, 13(1), 11-21. https://doi.org/10.1007/s40271-019-00389-4

Kuyken, W., Crane, R., \& Williams, M. (2012). Mindfulness-based Cognitive Therapy (MBCT) Implementation Resources. University of Oxford.

Kuyken, W., Warren, F. C., Taylor, R. S., Whalley, B., Crane, C., Bondolfi, G., Hayes, R., Huijbers, M., Ma, H., Schweizer, S., Segal, Z., Speckens, A., Teasdale, J. D., Van Heeringen, K., Williams, M., Byford, S., Byng, R., \& Dalgleish, T. (2016). Efficacy of mindfulness-based cognitive therapy in prevention of depressive relapse: An individual patient data meta-analysis from randomized trials. JAMA Psychiatry, 73(6), 565-574. https://doi.org/10.1001/jamapsychiatry.2016.0076

Langlands, R. L., Jorm, A. F., Kelly, C. M., \& Kitchener, B. A. (2008). First aid for depression: A Delphi consensus study with consumers, carers and clinicians. Journal of Affective Disorders, 105(1-3), 157-165. https://doi.org/10.1016/j.jad.2007.05.004

Lindahl, J. R., Fisher, N. E., Cooper, D. J., Rosen, R. K., \& Britton, W. B. (2017). The varieties of contemplative experience: A mixed-methods study of meditation-related challenges in Western Buddhists. PLoS ONE, 12(5), e0176239. https://doi.org/10. 1371/journal.pone.0176239

Lovas, D. A., \& Schuman-Olivier, Z. (2018). Mindfulness-based cognitive therapy for bipolar disorder: A systematic review. Journal of Affective Disorders, 240, 247-261. https://doi.org/ 10.1016/j.jad.2018.06.017

Mackenzie, M. B., Abbott, K. A., \& Kocovski, N. L. (2018). Mindfulness-based cognitive therapy in patients with depression: Current perspectives. Neuropsychiatric Disease and Treatment, 14, 1599-1605. https://doi.org/10.2147/NDT.S160761

Mason, O., \& Hargreaves, I. (2001). A qualitative study of mindfulness-based cognitive therapy for depression. British Journal of Medical Psychology, 74(2), 197-212. https://doi.org/10.1348/ 000711201160911

McCartney, M., Nevitt, S., Lloyd, A., Hill, R., White, R., \& Duarte, R. (2021). Mindfulness-based cognitive therapy for prevention and time to depressive relapse: Systematic review and network meta-analysis. Acta Psychiatrica Scandinavica, 143(1), 6-21. https://doi.org/10.1111/acps.13242

Mindfulness All Party Parliamentary Group. (2015). Mindful nation $U K$. Westminster, London, UK. Retrieved from https://www. themindfulnessinitiative.org/mindful-nation-report

Morone, N. E., Moore, C. G., \& Greco, C. M. (2017). Characteristics of adults who used mindfulness meditation: United States, 2012. Journal of Alternative and Complementary Medicine, 23(7), 545-550. https://doi.org/10.1089/acm.2016.0099

National Institute for Health and Clinical Excellence. (2017). Depression in Adults. Recognition and Management. (CG90). Retrieved from https://www.nice.org.uk/guidance/cg90 
NHS England and Health Education England. (2016). Adult IAPT Workforce Census Report. NHS.

Ninomiya, A., Sado, M., Park, S., Fujisawa, D., Kosugi, T., Nakagawa, A., Shirahase, J., \& Mimura, M. (2020). Effectiveness of mindfulness-based cognitive therapy in patients with anxiety disorders in secondary-care settings: A randomized controlled trial. Psychiatry and Clinical Neurosciences, 74(2), 132-139. https://doi.org/10.1111/pcn.12960

Puddicombe (2010). Headspace. [Mobile application software]. https://www.headspace.com/

QSR International. (1999). NVivo Qualitative Data Analysis Software [Software]. (Version 12). QSR International. Available from https://qsrinternational.com/nvivo/nvivo-products/

Rodrigues, M. F., Nardi, A. E., \& Levitan, M. (2017). Mindfulness nos transtornos do humor e ansiedade: Uma revisão da literatura. Trends in Psychiatry and Psychotherapy, 39(3), 207-215. https://doi.org/10.1590/2237-6089-2016-0051

Rycroft-Malone, J., Gradinger, F., Griffiths, H. O., Crane, R., Gibson, A., Mercer, S., Anderson, R., \& Kuyken, W. (2017). Accessibility and implementation in the UK NHS services of an effective depression relapse prevention programme: Learning from mindfulness-based cognitive therapy through a mixed-methods study. Health Services and Delivery Research, 5(14), 1-190. https://doi. org/10.3310/hsdr05140

Rycroft-Malone, J., Gradinger, F., Owen Griffiths, H., Anderson, R., Crane, R. S., Gibson, A., Mercer, S. W., \& Kuyken, W. (2019). "Mind the gaps": The accessibility and implementation of an effective depression relapse prevention programme in UK NHS services: Learning from mindfulness-based cognitive therapy through a mixed methods study. British Medical Journal Open, 9(9), e026244. https://doi.org/10.1136/bmjopen-2018-026244

Santorelli, S., Meleo-Meyer, F., \& Koerbel, L. (2017). Mindfulnessbased stress reduction (MBSR) authorized curriculum guide. Center for Mindfulness in Medicine, Health Care, and Society (CFM)

Segal, Z. V., Williams, J. M. G., \& Teasdale, J. D. (2013). Mindfulnessbased Cognitive Therapy for Depression. Guildford Press.
Strege, M. V., Swain, D., Bochicchio, L., Valdespino, A., \& Richey, J. A. (2018). A pilot study of the effects of mindfulness-based cognitive therapy on positive affect and social anxiety symptoms. Frontiers in Psychology, 9, 866. https://doi.org/10.3389/fpsyg. 2018.00866

Turoff, M., \& Linstone, H. A. (1975). The Delphi Method-Techniques and applications. Addison-Wesley Pub. Co.

Van Dam, N. T., van Vugt, M. K., Vago, D. R., Schmalzl, L., Saron, C. D., Olendzki, A., Meissner, T., Lazar, S. W., Kerr, C. E., Gorchov, J., Fox, K. C. R., Field, B. A., Britton, W. B., Brefczynski-Lewis, J. A., \& Meyer, D. E. (2018). Mind the hype: A critical evaluation and prescriptive agenda for research on mindfulness and meditation. Perspectives on Psychological Science, 13(1), 36-61. https:// doi.org/10.1177/1745691617709589

Veugelers, R., Gaakeer, M. I., Patka, P., \& Huijsman, R. (2020). Improving design choices in Delphi studies in medicine: The case of an exemplary physician multi-round panel study with $100 \%$ response. BMC Medical Research Methodology, 20(1), 156. https://doi.org/10.1186/s12874-020-01029-4

Williams, J. M. G., Crane, C., Barnhofer, T., Brennan, K., Duggan, D. S., Fennell, M. J. V., Hackmann, A., Krusche, A., Muse, K., Von Rohr, I. R., Shah, D., Crane, R. S., Eames, C., Jones, M., Radford, S., Silverton, S., Sun, Y., Weatherley-Jones, E., Whitaker, C. J., ... Russell, I. T. (2014). Mindfulness-based cognitive therapy for preventing relapse in recurrent depression: a randomized dismantling trial. Journal of Consulting and Clinical Psychology, 82(2), 275-286. https://doi.org/10.1037/a0035036

Williams, K., \& Birtwell, K. (2018). The double-edged sword of mindfulness: maintaining integrity whilst increasing access. Clinical Psychology Forum, 306. http://man.ac.uk/04Y6Bo

Publisher's Note Springer Nature remains neutral with regard to jurisdictional claims in published maps and institutional affiliations. 